Open Access

\title{
Renal Dysfunction in Acute Heart Failure
}

\author{
Seong Woo Han, $\mathrm{MD}^{1}$ and Kyu Hyung Ryu, $\mathrm{MD}^{2}$ \\ ${ }^{1}$ Cardiovascular Center, Korea University, Guro Hospital, Seoul, \\ ${ }^{2}$ Department of Cardiovascular Medicine, Konkuk University Medical Center, Seoul, Korea
}

\begin{abstract}
During treatment of acute heart failure (AHF), worsening renal function is often complicated and results in a complex clinical course. Furthermore, renal dysfunction is a strong independent predictor of long-term adverse outcomes in patients with AHF. Traditionally, the predominant cause of renal dysfunction has been attributed to impairment of cardiac output and relative underfilling of arterial perfusion. Recently, emerging data have led to the importance of venous congestion and elevated intra-abdominal pressure rather than confining it to impaired forward cardiac output as the primary driver of renal impairment. Relief of congestion is a major objective of AHF treatment but therapy is still based on the administration of loop diuretics. The results of the recently performed controlled studies for the assessment of new treatments to overcome resistance to diuretic treatment to protect kidneys from untoward effects have been mostly neutral. Better treatment of congestion in heart failure remains a major problem. (Korean Circ J 2011;41:565-574)
\end{abstract}

KEY WORDS: Acute heart failure; Kidney function; Cardiorenal syndrome.

\section{Introduction}

Acute heart failure (AHF) is a major source of hospitalization and mortality. Patients with AHF usually present with severe dyspnea due to pulmonary congestion which is the hallmark of AHF. Therefore, elimination of excess fluid should be the primary target of treatment. Also, there is substantial evidence that fluid accumulation is associated with morbidity, mortality, and readmission with heart failure (HF) ${ }^{1-4)}$ Kidney is the main exit of congestion, but many numbers of AHF patients have accompanying renal dysfunction or experienced worsening of renal function during hospitalization. The heart and kidney are very closely related. Thus derangement of cardiac function can make renal dysfunction, recently referred to as "cardiorenal syndrome (CRS)" or inversely as "renocardiac syndrome". In 2008, Ronco et al. ${ }^{5)}$ classified CRS

Correspondence: Kyu Hyung Ryu, MD, Department of Cardiovascular Medicine, Konkuk University Medical Center, 4-12 Hwayang-dong, Gwangjin-gu, Seoul 143-729, Korea

Tel: 82-2-2030-6063, Fax: 82-2-2030-6069

E-mail: khryumd@hanmail.net

- The authors have no financial conflicts of interest.

(a) This is an Open Access article distributed under the terms of the Creative Commons Attribution Non-Commercial License (http://creativecommons.org/licenses/by-nc/3.0) which permits unrestricted non-commercial use, distribution, and reproduction in any medium, provided the original work is properly cited. into 5 subtypes, as showed in Table 1, by primarily affected organ (heart or kidney) and course of injury (acute or chronic). By this classification, type 1 CRS, which is the development of renal dysfunction in clinical situation of AHF, is the topic of our discussion and has been found to be more prevalent in hospitalized AHF patients.

Although, it is well established that patients who are admitted with AHF and renal dysfunction have worse outcomes, there is limited data for evidence-based therapeutic approaches. $^{6-8)}$ This is most likely because AHF is not a specific clinical-pathologic event and is not caused by a well-defined pathophysiologic mechanism (like acute coronary thrombosis), but instead results from various factors. AHF patients may manifest either 1) rapid accumulation of fluid in the lung, 2) progressive systemic congestion, or 3) clinical findings associated with reduced cardiac output. In addition, it is very difficult to test the impact of specific interventions, because these patients are inherently unstable and there are so many available treatment options and lack of appropriate target endpoints. For these reasons, there is a paucity of useful clinical trial evidence in patients with AHF, which results in a situation where most guideline recommendations for managing this syndrome are derived from "expert" opnions, unsupported by solid outcome data. ${ }^{9-11)}$

However, there is continuous accumulation of clinical data from well-controlled clinical trials for the diagnosis and mana- 
Table 1. Classification of CRS

\begin{tabular}{|c|c|c|c|}
\hline Type & Character & Proposed mechanism & Clinical setting \\
\hline Type 1 & Acute CRS & $\begin{array}{l}\text { Abrupt worsening of cardiac function } \\
\text { leading to kidney injury }\end{array}$ & $\begin{array}{l}\text { Acute cardiogenic shock, acute } \\
\text { decompensated HF }\end{array}$ \\
\hline Type 2 & Chronic CRS & $\begin{array}{l}\text { Chronic cardiac abnormalities causing } \\
\text { progressive chronic kidney injury }\end{array}$ & $\begin{array}{l}\text { Chronic heart failure cause chronic } \\
\text { renal hypoperfusion }\end{array}$ \\
\hline Type 3 & Acute renocardiac syndrome & $\begin{array}{l}\text { Abrupt worsening of renal function } \\
\text { causing acute cardiac disorder }\end{array}$ & $\begin{array}{l}\text { ARF, Acute GN cause acute pulmonary } \\
\text { edema, arrhythmia }\end{array}$ \\
\hline Type 4 & Cronic renocardiac syndrome & $\begin{array}{l}\text { Chronic kidney disease contributing } \\
\text { to decreased cardiac function }\end{array}$ & $\begin{array}{l}\text { Chronic renal disease cause cardiac } \\
\text { hypertrophy, decreased cardiac function }\end{array}$ \\
\hline Type 5 & Secondary CRS & $\begin{array}{l}\text { Systemic condition causing both cardiac } \\
\text { and renal dysfunction }\end{array}$ & Diabetes, sepsis \\
\hline
\end{tabular}

CRS: cardiorenal syndrome, HF: heart failure, ARF: acute renal failure, GN: glomerulonephritis

gement for AHF and accompanying renal dysfunction. In this review, we discuss the pathophysiology of renal dysfunction associated with AHF, early detection modalities, and finally, current therapeutic strategies. We used the terminology "renal dysfunction in AHF" rather than "CRS". As noted above, some authors used the "CRS" in a variable clinical situation, but our point of discussion is focused on renal dysfunction in the setting of AHF, especially worsening during AHF treatment.

\section{Prevalence and Prognosis}

\section{Accompanying renal dysfunction}

American College of Cardiology/American Heart Association guidelines for " $\mathrm{HF}$ data standard" suggested that chronic renal disorder can be categorized in to 4 groups as mild, moderate, severe renal insufficiency and chronic renal failure by using the estimated glomerular filtration rate (eGFR); 60-89, $30-59,15-29,<15 \mathrm{~mL} / \mathrm{min} / 1.73 \mathrm{~m}^{2}$ respectively.9) Although, GFR can be estimated by various formulas, simplified Modification of Diet in Renal Disease (MDRD) formula (186.3× sCr ${ }^{-1.154} \times$ age $^{-0.203}$, female: MDRD $\times 0.742$, Black or non-white: $\mathrm{MDRD} \times 1.212)$ is simple, and only serum creatinine and age are needed for calculation. It is also a reliable predictor for prognosis in HF patients. ${ }^{12}$ It is not appropriate to use a single measurement of serum creatinine for the evaluation of renal function, because serum creatinine levels can be largely influenced by age, muscle mass etc. However, many clinical trials and registry data used serum creatinine levels for the diagnosis of renal dysfunction.

In large nationwide registry data in USA and Europe, 20.4\% of patients had serum $\mathrm{Cr}>2.0 \mathrm{mg} / \mathrm{dL}$ in Acute Decompensated Heart Failure National Registry (ADHERE), and 18\% in EURO-Heart survey ( $40 \%$ in old EU). In Korean Heart Failure (Kor-HF) registry, $15.2 \%$ of AHF patients showed level of serum $\mathrm{Cr}>2.0 \mathrm{mg} / \mathrm{dL}{ }^{12) 13)}$ In the Evaluation Study of Congestive Heart Failure and Pulmonary Artery Catheterization Effectiveness (ESCAPE), the proportion of patients with an eGFR $<60 \mathrm{~mL} / \mathrm{min}$ was $31.4 \% .{ }^{14)}$
Accompanying renal dysfunction is one of the main independent risk factors for prolonged hospitalization, rehospitalization, and short- and long-term mortality. ${ }^{6-8)}$ In patients with HF, compared to left ventricular ejection fraction (LVEF) or NYHA functional class, baseline GFR has been demonstrated to be a stronger predictor for all-cause mortality. Likewise, a decrease in GFR is directly associated with the rate of in-hospital mortality. In a meta-analysis, Smith et al. ${ }^{15)}$ reported that, annual mortality rates were $26 \%$ in patients without renal dysfunction, $41 \%$ in the patients with any impairment of renal function and $51 \%(\mathrm{p}<0.001)$ in patients with moderate to severe impairment $(\mathrm{p}<0.001)$.

\section{Worsening renal function}

Patients hospitalized for AHF often develop worsening renal function. It occurs in 25-30\% of acute HF admissions and is more likely in patients with renal dysfunction at baseline, diabetes and previous $\mathrm{HF}^{16-19)}$ In Kor-HF registry, worsening of renal function, defined as increasing serum creatinine levels more than 1.5 times baseline, happened in 21.5\% of AHF patients. ${ }^{13)}$ Although there is no concrete criteria, worsening renal function is often defined as an increase in $\mathrm{sCr} \geq 0.3 \mathrm{mg} /$ $\mathrm{dL}$ from baseline value. In a meta-analysis, prior mentioned, of 16 studies including 80,098 patients, worsening renal function was associated with a $47 \%$ increase in one-year mortality, with a $33 \%$ increase in mortality for every $1 \mathrm{mg} / \mathrm{dL}$ increase in $\mathrm{sCr}$.

Forman et al. ${ }^{16)}$ reported that from 1,004 AHF patients, worsening renal function was related with 7.5 times higher relative risk ratio for in hospital death and 2.1 times higher for complication. In Kor-HF registry, in-hospital mortality was significantly higher $(13.2 \%$ vs. $5.4 \%, \mathrm{p}<0.01)$ and duration of intensive care unit (ICU) stay and hospitalization were prolonged in patients with worsening renal function. ${ }^{13)}$

Sometimes, worsening renal function dose not persist, but in two-thirds of this condition could to be persist and associated with worse outcomes. Due to confounding factors (etiology, co-morbidities, medications etc.) and baseline renal func- 
tion, the real impact of worsening renal failure on prognosis is unclear. Additionally, the lack of a clear definition of worsening renal function, and heterogeneity of currently available biomarkers of renal function provide a limitation for the interpretation of these results.

\section{Pathophysiology}

Heart failure is characterized by complex cardiac, renal, and vascular interactions, mediated through both hemodynamic and neurohumoral mechanisms (Fig. 1). Increased vascular stiffness limits the ability of the intravascular space to accomodate salt and fluid loads. Endothelial dysfunction contributes to vasoconstriction and increased afterload. Renal dysfunction may limit sodium excretion and drives activation of the renin-angiotensin-aldosterone axis. Although, it is not yet clearly identified the mechanism of progressive renal dysfunction in AHF, following factors are proposed as pathophysiologic alterations of this syndrome.

\section{Hemodynamic abnormalities}

\section{Low cardiac output}

Patients with HF may progress to a chronic low cardiac output state with systemic and renal hypoperfusion and cause activation of rennin-agiotensin-aldosterone system (RAAS) and sympathetic sympathetic nervous system (SNS) leading to sodium retention, volume expansion and ventricular remodeling. ${ }^{20211}$ Theoretically, the progressive impairment of renal function may result from inadequate renal perfusion secondary to reduced cardiac output. However, several data suggest that hemodynamic alteration from low cardiac output is not the only determinant of reduced GFR, and management of patients with CRS based only on improvement of renal blood flow does not lead to a better prognosis. ${ }^{22)}$ This hypothesis is supported by the observation that renal dysfunction occurs at similar rates in patients with either systolic or diastolic dysfunction. ${ }^{23)}$

\section{Elevated central venous pressure}

Basically, the pressure gradient between glomerular afferent and efferent arterioles makes the drive force for glomerular filtration. In HF patients, increased central venous pressure (CVP) can be transmitted to the glomerular efferent arteriole with a reduction of the glomerular filtration pressure gradient and cause a fall of GFR. Additionally, it was postulated that transmitted pressure to the renal vein causes increased renal interstitial pressure and this may lead to renal parenchymal hypoxic state. In practical terms, Mullens et al. ${ }^{24)}$ reported that in 145 patients of AHF, only the CVP was the most important determinant of the development of worsening renal function. In addition, Damman et al. ${ }^{25}$ found that CVP was the most important determinant of renal dysfunction and the most important independent predictor of mortality in 2,557 patients hospitalized for cardiac catheterization. Notably, elevated jugular venous pulsations on physical examination and baseline right atrial pressure are related with elevated baseline serum creatinine ${ }^{26)}$ Recently, further studies have demonstrated that CVP has a close relationship with renal dysfunction in patients with $\mathrm{HF}^{27228)}$

\section{Adenosine}

Adenosine is released in response to increased sodium loading in the distal tubule, and via A1-receptors in the proximal tubule and afferent arterioles, mediates constriction of afferent arterioles and reduction of renal blood flow and GFR. Additionally, activation of $\mathrm{A} 1$ receptors induces release of rennin and enhances sodium re-absorption at the proximal tubule and reduces diuresis. ${ }^{29)}$ Thus, adenosine may be an important mediator for renal dysfunction after intensive diuretic treatment with high dose loop diuretics for AHF. Unfortunately, studies with type 1a-adenosine receptors blocking agents have failed to demonstrate a significant beneficial effect in renal function in $\mathrm{AHF}^{30)}$

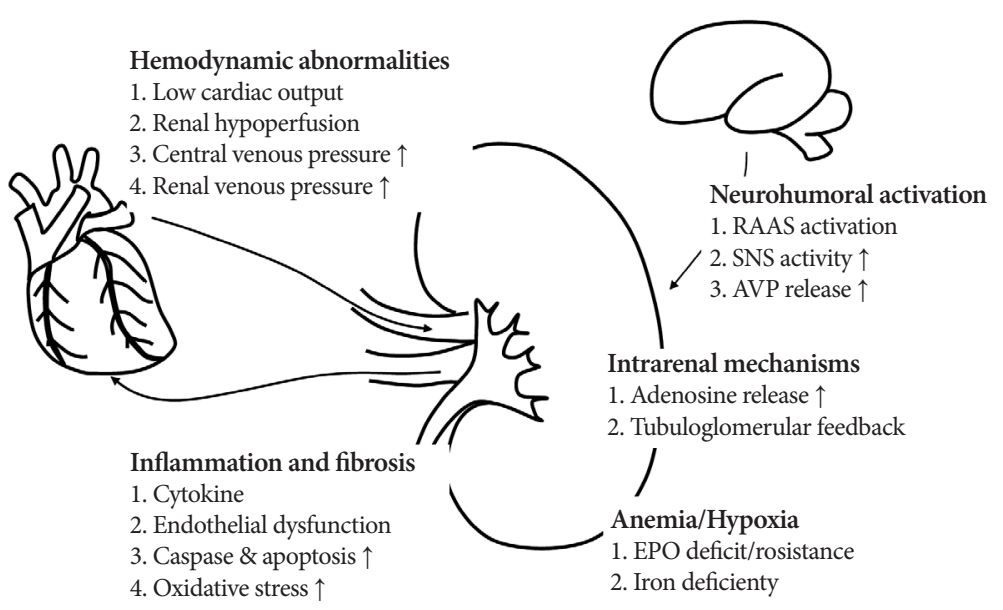

Fig. 1. Pathophysiological mechanisms of worsening renal function in acute heart failure. 


\section{Neurohumoral mechanism}

When HF develops, RAAS and SNS are activated as a protection mechanism for renal hypoperfusion. ${ }^{31{ }^{322}}$ This is essential in dangerous situations like gastrointestinal bleeding or trauma. However, in the case of chronically stimulated state, the consequence of these conditions is deleterious on the heart and kidney.

Increased renin secretion is demonstrated in HF and generation of angiotensin II from angiotensin I is enhanced by rennin. Angiotenin II is a potent constrictor of arterioles and therefore increases the afterload resulted in decreased cardiac output. Angiotenin II stimulates the SNS and aldosterone release as well, and these cause further constriction of renal vasculature. Constriction of afferent arterioles by angiotensin II and SNS reduces renal blood flow and GFR, and causes increased proximal tubular sodium reabsoprtion. ${ }^{32) 33}$

Activation of SNS initially has a protective role for maintaining cardiac output by positive chronotropic and inotropic effects. Like RAAS activation, chronic activation of SNS also resulted in numerous deleterious effects on the cardiovascular system and kidneys. ${ }^{34}$ In the kidney, activation of SNS also causes further activation of RASS and leads to inadequate fluid and sodium retention. Reduced renal perfusion pressure during HF causes constriction of afferent arterioles, and a further decrease in renal blood flow and GFR. When HF develops, these effects are more exaggerated due to higher release and lower clearance of catecholamines.

Arginine vasopressin (AVP) is released by osmotic stimuli, blood pressure, and cardiac factors. In usual situations, low osmolarity suppresses AVP release, but in HF state, due to non-osmotic baroreceptor mechanisms, there is a marked increase in AVP release even with hyponatremia. AVP activates the V2 receptor in the collecting duct and increases the permeability of water channels resulting in water retention. AVP stimulates the V1a receptors of the vascular smooth muscle that results in vasoconstriction of the arterial and venous system. $^{35-37)}$

\section{Evaluation of Renal Dysfunction}

\section{Conventional markers (blood urea nitrogen, creatinine)}

Usually, evaluation of renal dysfunction is based on change of serum creatinine $(\mathrm{sCr})$. However, there are many limitations in using $\mathrm{sCr}$ as a marker of renal dysfunction. Serum creatinine is largely influenced by age and related to other variables including sex and muscle mass. ${ }^{38339)}$ Additionally, $\mathrm{sCr}$ level is not sensitive for the detection of renal injury. It is demonstrated that, kidney damage can occur without producing a change in eGFR calculated by sCR. The amount of changes in serum creatinine after renal injury is highly dependent on baseline kidney function: in case of normal baseline renal function, sCr levels start to increase at advanced stage of renal injury, whereas when renal dysfunction is already present, it can be overestimated due to the $\mathrm{sCr}$ level changing a relatively large amount (e.g., 50\% increase in $\mathrm{sCr}$ with baseline level $1.0 \mathrm{mg} / \mathrm{dL}$ and $2.0 \mathrm{mg} / \mathrm{dL}$ result in $1.5 \mathrm{mg} / \mathrm{dL}$ and $3.0 \mathrm{mg} / \mathrm{dL}$ respectively). ${ }^{40)}$ Also, there is an exponential relationship between $\mathrm{sCr}$ level and estimated GFR, therefore, worsening renal function may be better defined by either an absolute increase from baseline and a percent increase. Recently, it has been reported that renal dysfunction defined as both a $\geq 0.3 \mathrm{mg} / \mathrm{dL}$ increase plus $\geq 25 \%$ increase from baseline values was an independent prognostic factor, whereas it had no independent prognostic value when defined only by absolute changes from baseline. ${ }^{19)}$

Because sCr has slow kinetics, marked reduction in eGFR may cause relatively small changes in $\mathrm{sCr}$ levels in the early stage of acute kidney injury (24-48 hours). In addition, sCr kinetics are dependent on baseline renal function so that the time interval from kidney injury to $50 \%$ increase in $\mathrm{sCr}$ ranges from 4 hours with normal baseline renal function to more than 1 day with underlying advanced renal dysfunction. ${ }^{41)}$ More importantly, $\mathrm{sCr}$ level is a marker of renal function rather than kidney injury, so, increased sCr levels are not always representative of kidney injury.

Blood urea nitrogen (BUN) was shown to be an important predictor of morbidity and mortality in patients with $\mathrm{HF}^{8{ }^{82-44)}}$ The major difference between $\mathrm{sCr}$ and $\mathrm{BUN}$ is related to the reabsorption of BUN in the renal tubules. It is mediated by AVP, sympathetic nervous activity, renin-angiotensin-aldosterone system and to sodium reabsorption with volume status. ${ }^{45)}$ Therefore, intensive diuretic treatment, enhance urea reabsorption and increase BUN. Recently, Testani et al. ${ }^{46)}$ reported that, in Beta-blocker Evaluation of Survival trial, elevated serum BUN level with high dose loop diuretics was associated with high mortality in chronic HF (Fig. 2). BUN is also dependent on nitrogen production and in conditions causing an increase in protein catabolism, such as cachexia and gastrointestinal hemorrhage. ${ }^{47)}$

\section{Novel markers}

\section{Neutrophil gelatinase-associated lipocalin}

Neutrophil gelatinase-associated lipocalin (NGAL) is the most promising emerging biomarker for acute kidney injury. In humans, NGAL is a small $25 \mathrm{kDa} 178$ amino acid chain, expressed by neutrophils and other epithelial cells in the proximal collecting tubule. ${ }^{48}$ The physiological role of NGAL in renal ischemia or toxin induced kidney injury, may be to decrease injury by reducing apoptosis and increasing the normal proliferation of kidney tubule cells. It is freely filtered by the glomerulus and completely reabsorbed in the tubules. Several studies in various clinical settings have demonstrated 


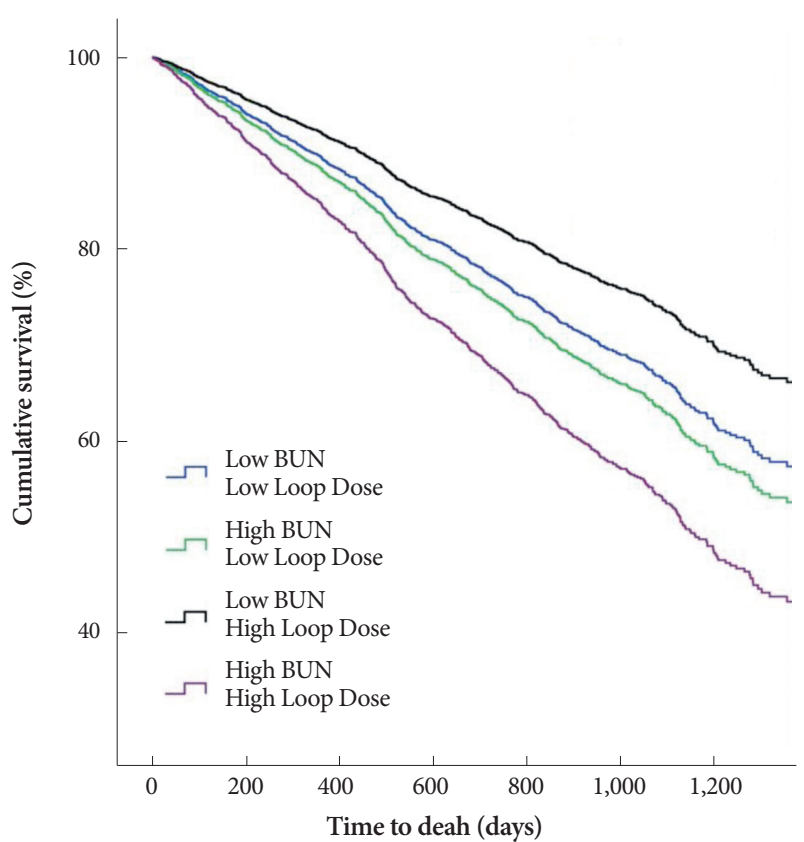

Fig. 2. Adjusted survival plots grouped by BUN and high dose loop diuretics use. ${ }^{46)}$

the ability of NGAL to allow early identification of acute kidney injury, including cardiac surgery, contrast studies, ICUs and the emergency department. ${ }^{49)}$ In patients with acute HF, NGAL can predict worsening renal function more accurately in an earlier stage than sCr. Aghel et al. ${ }^{50)}$ reported that in 91 patients admitted for AHF, worsening renal function was observed in $38 \%$ within 5 days of follow-up. Patients who developed worsening renal function had significantly higher median serum NGAL levels ( $194 \mathrm{ng} / \mathrm{mL}$ vs. $128 \mathrm{ng} / \mathrm{mL}$, p=0.001) at admission and it was associated with an increase in risk of developing worsening renal function. ${ }^{50}$ Levels of urinary NGAL may be more sensitive as makers for tubular damage than serum levels. However, more studies are needed to confirm its usefulness in clinical practice and provide exact cut-off levels for different clinical settings.

\section{Cystatin C}

Cystatin C (CysC) is a $13.3 \mathrm{kDa}, 122$-amino acid protein, member of the superfamily of cysteine protease inhibitors, and is synthesized by all nucleated cells at a constant production rate. It is freely filtered by the glomerulus, and not secreted but slightly metabolized by tubular epithelial cells. Compared with sCr, $\mathrm{CycC}$ has been demonstrated to be independent of age and sex. ${ }^{5152)}$ Thus, serum $\mathrm{Cys} C$ would be one of the ideal markers to estimate GFR. It has been demonstrated that $\mathrm{CysC}$ is a more sensitive marker than $\mathrm{SCr}$ for small changes in GFR and could be an earlier indicator of mild renal failure. In patients with $\mathrm{AHF}, \mathrm{Cys} C$ is an independent factor for longer length of hospitalization $(\mathrm{p}=0.01)$ and higher in-hospital and post-discharge mortality. Interestingly, elevated serum $\mathrm{CysC}$ is associated with higher mortality at
12 months in patients with normal $\mathrm{sCr}$ level $(\mathrm{p}<0.0001) .{ }^{53)}$

\section{Other biomarkers}

Kidney injury molecule-1 (KIM-1) is a transmembrane protein expressed in proximal tubule cells during renal diseases associated with either proteinuria, toxic or ischemic damage. It is expressed in post-ischemic kidneys while remaining undetectable in healthy subjects, and showing that it expresses during tubule-interstitial injury and inflammation. Urinary KIM-1 levels correlate with tubular KIM-1 expression in experimental models and in human renal disease. ${ }^{54)}$ In chronic HF, KIM-1 demonstrated a correlation with plasma N-terminal pro-brain natriuretic peptide (BNP) levels and, independently of GFR values, was associated with an increased risk of death or HF hospitalizations. KIM-1 is highly sensitive to acute tubular injury but in the setting of acute HF its role is still unsettled. ${ }^{56)}$

$\mathrm{N}$-acetyl-beta-D-glucosaminidase (NAG) is produced in the proximal tubule and after tubular injury, released into the urine. In patients with HF, urinary NAG levels, as KIM-1, were associated with plasma $\mathrm{N}$-terminal pro-BNP levels and increased risk of death or HF hospitalizations regardless of GFR. ${ }^{55)}$ In addition, NAG levels were correlated with GFR $(\mathrm{p}=0.001)$ and effective renal plasma flow $(\mathrm{p}=0.006)$, suggesting that this marker can detect decreased renal perfusion in patients with low cardiac output As for KIM-1, data in AHF are lacking. The accuracy of this marker in acute kidney injury suggesting its usefulness in the acute setting and further studies are needed in order to define its role in AHF. Other novel protein biomarkers for the early detection of kidney are listed and briefly introduced in Table 2 .

\section{Treatment}

In patients with acute HF, markedly activated neurohormonal axis and worsening renal function ultimately ensue to venous congestion and elevated CVP, which results in a vicious cycle. Thus, the focus of the treatment should be on reducing the congestion with as little hemodynamic compromise as possible.

\section{Relief of congestion}

\section{Diuretics}

Current practice guidelines recommend loop diuretics as the mainstay of therapy in patients with congestive symptoms in the setting of AHF. ${ }^{11)}$ In ADHERE registry, $88 \%$ of patients receive loop diuretics, mainly intravenously. ${ }^{1)}$ There are no randomized controlled trials to evaluate the beneficial effects of loop diuretics. However, it is evident that congestion correlates with mortality, therefore, patients with AHFS should be treated for the relief of congestion. In patients who have se- 
Table 2. Protein biomarkers for the early detection of acute kidney injury

\begin{tabular}{ll}
\hline Biomarker & Associated injury \\
\hline Cystatin C & Proximal tubule injury \\
KIM-1 & Ischemia and nephrotoxins \\
N-GAL (lipocalin) & Ischemia and nephrotoxins \\
NHE3 & Ischemia, pre-renal, post-renal AKI \\
Cytokines (IL-6, IL-8, & Toxic, delayed graft function \\
$\begin{array}{l}\text { IL-18) } \\
\text { Actin-actin } \\
\text { depolymerizing F }\end{array}$ & Ischemia and delayed graft function \\
$\alpha$-GST & Proximal tubule injury, acute rejection \\
$\pi$-GST & Distal tubule injury, acute rejection \\
L-FABP & Ischemia and nephrotoxins \\
Netrin-1 & Ischemia and nephrotoxins, sepsis \\
Keratin-derived & Ischemia and graft function \\
chemokines &
\end{tabular}

GST: glutathione S-tranferase, KIM: kidney injury molecules, LFABP: L-type fatty acid binding protein, NGAL: neutrophil gelatinase-associated lipocalin, NHE: sodium-hydrogen exchanger

Table 3. Causes of resistance to furosemide

\section{Inadequate diuretic dose}

Excess sodium intake

Delayed intestinal absorption of oral diuretics

Delayed diuretic excretion into the urine

$\mathrm{Na}+$ reabsorption at diuretic-insensitive site in the nephron

vere congestion and renal dysfunction, diuresis may improve kidney function, possibly through relieving the central venous congestion. What is more beneficial for controlling congestion intermittent versus bolus, or high dose versus conventional dosage of loop diuretics is a recurring question. The Diuretic Optimization Strategies Evaluation (DOSE) trial is the first randomized, controlled exploration of a management strategy in loop diuretics in AHFS patients. In this study, there was no statistically significant difference in symptom relief or renal function at 72 hours between intermittent versus continuous infusion or low dose versus high dose strategy. ${ }^{56)}$

There are several mechanisms for diuretic resistance: inadequate dose, excess sodium intake, delayed intestinal absorption, decreased excretion of diuretics at action site, vigorous sodium reabsorption at other sites of nephron (Table 3). Experts recommend switching from intravenous to continuous infusion in patients who seem to be nonresponsive to diuretics. Although, for the relief of congestion and symptoms, loop diuretics are very effective, it should be considered that there are serious adverse effects associated with loop diuretics. ${ }^{57)}$ Electrolyte abnormalities mainly hyponatremia, hypokalemia and hypomagnesemia are frequently developed with these agents. The loop diuretics can cause increased release of renin and further stimulation of neurohormones and acute vasoconstriction after administration, so, even though urine out- put is substantially increased GFR can be reduced by loop diuretics induced vasoconstriction. ${ }^{58)}$ Another approach to overcome diuretic resistance is limitation of total daily sodium intake to less than $2 \mathrm{gm}$, and fluid restriction of less than 2 liters. When moderate hyponatremia $(<130 \mathrm{mEq} / \mathrm{L})$ exists, the patient should be educated for more aggressive fluid restriction. The pharmacologic approach to overcome resistance is to add another diuretic that acts in distal tubule, such as a thiazide or metolazone. Continuous infusion of loop diuretics may avoid rebound absorption of sodium that occur when serum levels of loop diuretics are low or reduce ototoxicity. But, as stated above, in the DOSE trial, there was no difference in outcome of mortality.

\section{Vasopressin antagonist}

Patients with acute decompensated HF often have an activation of AVP release. AVP causes water retention via vasopressin type 2 (V2) receptors in the collecting duct. The V2 receptor antagonists-"vaptans"-can induce free water diuresis and correction of hyponatremia in patients with HF. In Efficacy of Vasopressin Antagonism in Heart Failure Outcome Study With Tolvaptan trial, the efficacy of the selective V2 receptors antagonist, tolvaptan has been evaluated with 4,133 patients with $\mathrm{HF}$ for the outcomes, and symptoms/signs of $\mathrm{HF}$. Compared to placebo, tolvaptan was associated with greater improvement of symptoms, but no benefit on outcomes. There was no derangement of renal function throughout the study. ${ }^{59)}$ Other studies conducted on subjects with chronic HF showed neutral effects of vasopressin antagonists on renal function compared with furosemide. ${ }^{60)}$ Therefore AVP antagonists can be applied in the limited setting of HF patients with hyponatremia. However, antagonists for $\mathrm{V} 2$ receptors are not yet available in Korea.

\section{Adenosine antagonists}

As mentioned above, adenosine has a detrimental effect on renal hemodynamics. On the basis of this pathophysiological concept, adenosine A1 receptor antagonists have been investigated in patients with advanced HF. Many relatively small, controlled studies have been conducted for the evaluation of adenosine receptor antagonists including BG9719, KW-3902 (rolofylline), and could find renoprotective effects of A1 receptor blockers. Based on these results a large-scale controlled trial (PROTECT trial) was designed. In this trial, renal function was included among the components of the primary endpoint. Unfortunately, the results of PROTECT were neutral for the primary endpoint (dyspnea relief combined with the absence of worsening $\mathrm{HF}$ at 1 week and worsening renal function at 7 and 14 days) and for the pre-specified secondary outcomes (death from any cause or rehospitalization for cardiovascular or renal causes through day 60 and the proportion of patients with persistent renal impairment). ${ }^{30)}$ In con- 
clusion, the administration of rolofylline was not associated with favorable effects on renal outcomes. An important issue in the PROTECT trial was the excess of neurological complications observed in the rolofylline group. Therefore, adenosine receptor antagonist can not be recommended in HF patients with renal dysfunction.

\section{Correction of hemodynamic abnormalities}

\section{Dopamine}

When administered at low doses ( $\leq 2 \mu \mathrm{g} / \mathrm{kg}$ per min), dopamine may selectively improve renal blood flow through its action on DA1 receptors. Also, improvement of diuresis can be expected, even though small but favorable changes in renal function by administration of low dose dopamine occur. At intermediate doses (2-5 $\mu \mathrm{g} / \mathrm{kg}$ per min), dopamine interacts with the $\beta 1$-receptor, producing positive inotropic effects; this increase in cardiac output may be another favorable mechanism of the action of dopamine. ${ }^{6162)}$ In the recently completed Dopamine in Acute Decompensated Heart Failure (DAD-HF) trial, 60 patients with acute HF were randomly assigned to continuous 8 hours infusion of high-dose furosemide $(20 \mathrm{mg} / \mathrm{h})$ or low-dose furosemide $(5 \mathrm{mg} / \mathrm{h})$ plus lowdose dopamine $(5 \mathrm{mcg} / \mathrm{kg} / \mathrm{min})$. Both strategies had similar effects on hourly diuresis and dyspnea score. Worsening renal function was more frequently observed in the high-dose diuretic group (30\%), than in the dopamine group $(6.7 \%)(\mathrm{p}=$ $0.042){ }^{63)}$ Length of hospitalization and 60-day mortality or rehospitalization rates were similar between both groups. Even though the favorable outcome was observed, the small sample size and no favorable effect on major outcome (mortality, rehospitlalization and free from renal replacement therapy), it can not be directly applied as evidence.

\section{Other inotropics}

Because renal hypoperfusion due to low cardiac output can contribute to renal dysfunction in acute HF, administration of inotropic agents might be useful. Dobutamine administration has been associated with an increase of diuresis and natriuresis, and these effects are likely caused by the increase in cardiac output. ${ }^{64)}$ Recently reported data showed that in 88 patients with acute HF randomized to levosimendan or dobutamine, only levosimendan administration was associated with an improvement in measured eGFR $(+15$ and $+45 \%$ from baseline after 24 and 72 hours, respectively), whereas there was no change in the dobutamine group. ${ }^{65)}$ However, these data were obtained in small, single-center studies, and were not confirmed in the large Survival of Patients With Acute Heart Failure in Need of Intravenous Inotropic Support (SURVIVE) trial. ${ }^{66}$

There are possible suggestions to improve of renal function not related with increased cardiac output but associated with relief of venous congestion and decreased intra-glomeluar pressure. The absence of clinical benefit associated with increased cardiac index was shown in the Outcomes of a Prospective Trial of Intravenous Milrinone for Exacerbations of Chronic Heart Failure study, and in the ESCAPE trial, which found no association between baseline renal function and cardiac index. ${ }^{814)}$ These results seem to confirm that, increased renal venous pressure and intraglomerular pressure, but not low cardiac output, could be the main determinants of renal dysfunction and diuretic resistance, and therefore represent the therapeutic target, whereas inotropic agents should not be the treatment of choice for this condition.

\section{IV vasodilators}

Intravenous vasodilators-nitrates and sodium nitroprusside-are frequently administrated, in patients with AHF with normal or high blood pressure. In KoHF registry, 35.8\% of patients were treated with intravenous nitrate infusion. ${ }^{13)}$ At a low dose, nitroglycerin dilates venules and decreases cardiac filling pressures and myocardial oxygen demand; at higher doses, it decreases afterload and augments cardiac output. Sodium nitroprusside acts on vascular smooth muscle, and induce arterial and venous vasodilation. ${ }^{67(68)}$ Although, in patients with HF, nitrates and sodium nitroprusside do not have a direct influence on fluid overload and do not improve renal blood flow, compared with high doses of furosemide alone, treatment with nitrates added to low doses of furosemide has been shown to be associated with better outcomes in patients with acute $\mathrm{HF}$ and normal to high blood pressure. Relaxin causes systemic and renal vasodilatory effects via nitric oxide pathways and the endothelin type B receptor, lead to systemic and renal vasodilation and increased arterial compliance; triggering similar changes could potentially be beneficial in the treatment for patients with $\mathrm{HF}^{69)}$

On the basis of small sized data, a preliminary double blind, placebo-controlled, parallel group, dose-ranging study of relaxin for the treatment of patients with acute HF (Pre-RELAXAHF) was designed to assess the effect of intravenous relaxin compared with placebo in 234 patients with acute HF, and mild-to-moderate renal insufficiency. Despite previous data suggesting favorable effects on GFR and renal blood flow, relaxin did not show a clear effect on renal function, although a greater weight loss with less diuretic use was noted. The ongoing RELAX-AHF study will provide more elements.

\section{Nesiritide}

Nesiritide is a recombinant human BNP and can be categorized as a vasodilator. It enhances peripheral vasodilation, natriuresis, and diuresis through activation of guanylate cyclase pathways; moreover, it antagonizes the effects of the renin-angiotensin system, endothelin, and catecholamines. In the United States and other countries, it is approved for the treat- 
ment of congestive symptoms, in addition to diuretics, in patients with acutely decompensated HF. However, a subsequent meta-analyses of randomized trials evidenced untoward effects of nesiritide on renal function and mortality. In particular, patients with acute decompensated HF nesiritide significantly increased the risk of worsening renal function.

Recently, the Acute Study of Clinical Effectiveness of Nesiritide in Decompensated Heart Failure (ASCEND-HF) trial was performed to assess the effects of nesiritide on symptoms and outcomes of patients with acute HF. This study included 7,141 patients with acute decompensated HF, randomized to placebo or nesiritide. Unfortunately, it did not meet the pre-specified criteria for statistical significance. However, nesiritide was associated with a small improvement of dyspnea, without significant effects on outcomes. Thus, ASCEND-HF demonstrated that nesiritide is safe, but has only mild effects on symptoms, and no effects on outcomes. ${ }^{70)}$

\section{Neurohumoral Blockade}

Although, RAAS has an important role in renal dysfunction in acute HF syndrome, the role of the RAAS blockade with ACE inhibitors, angiotensin receptor blockers, direct renin inhibitors, or aldosterone antagonists in acute progressive stage of renal dysfunction is unclear. Additionally, patients with diuretic resistance and advanced HF frequently show intolerance to the hemodynamic and renal effects of RAA antagonists. Moreover, ACE inhibitors and angiotensin receptor blockers can lead to an acute decrease in GFR through the dilatory effect on the efferent arteriole. Thus, in patients with acute decompensated $\mathrm{HF}$, the risk of worsening renal function RAAS blockers were frequently hesitant to initiate them.

However, the benefits of ACE inhibitors are clear, and outcomes are extremely poor in individuals with $\mathrm{HF}$ in whom ACE inhibitors are held. In the Cooperative North Scandinavian Enalapril Survival Study, enalapril treated group showed increased mean serum creatinine, but had lower mortality rates. ${ }^{71)}$ These data suggest that some increase in creatinine and reduction in GFR (up to 30\%) using ACE inhibitors should be tolerated even in patients with renal dysfunction.

\section{Ultrafiltration}

Excess water can be removed by ultrafiltration using a semipermeable membrane in response to a transmembrane pressure gradient between the blood and filtrate side. The removed fluid by ultrafiltration is isotonic to plasma, and isotonic fluid loss may be a potentially better tool for the treatment of congestion in patients with HF who have an activation of primarily sodium retentive mechanisms. Compared with loop diuretics, relatively more sodium can be removed by ultrafiltration. In case of diuretic resistance, ultrafiltration have been used to decrease excessive fluid overload and in patients with significantly decreased renal function, to correct abnormalities in electrolyte levels and acid-base status. In the Relief for Acutely Fluid-Overloaded Patients With Decompensated Congestive Heart Failure there was marked weight loss and relief of HF symptoms, but no improvement of renal function. ${ }^{72)}$ In the Ultrafiltration versus Intravenous Diuretics for Patients Hospitalized for Acute Decompensated Heart Failure trial, there was a marked decrease in body weight, vasoactive drug requirement as well as hospital readmission over 90 days in the ultrafiltration arm. ${ }^{73)}$ However, this was associated with a trend towards higher-serum creatinine level in the first week of therapy in the ultrafiltration arm. The ongoing Cardiorenal Rescue Study in Acute Decompensated Heart Failure trial will further define the use of this treatment in patients with acute decompensated HF and acute renal dysfunction.

\section{Conclusions}

For treatment of patients with acute HF, clinicians are frequently faced with worsening renal dysfunction. The main driver of the pathophysiology and symptomatology is congestion and the focus of treatment should be relieving congestion without hemodynamic compromise. Unfortunately, every modality of treatment has dual effects - beneficial and detrimental - on this aspect. Loop diuretics relieve congestion but stimulate the neurohormones and reduce GFR. Inotropes improve hemodynamics but can potentially increase mortality and arrhythmias. Vasopressin antagonists have not been proven to decrease mortality in a large randomized control trial, although there are no large data sets on mixed receptor blockers. Natriuretic peptides may worsen kidney function and fail to show clinical benefit. Vasodilators can cause substantial hypotension while improving the hemodynamics. Therefore, it might be impossible to provide guidelines containing beneficial treatment modalities based on robust evidence. Accurate assessment for hemodynamic status with clinical parameters combined with newer biomarkers and more appropriate and effective interventions would help us to achieve optimal hemodynamic status and outcome of patients with acute HF syndrome.

\section{REFERENCES}

1) Adams KF Jr, Fonarow GC, Emerman CL, et al. Characteristics and outcomes of patients hospitalized for heart failure in the United States: rationale, design, and preliminary observations from the first 100,000 cases in the Acute Decompensated Heart Failure National Registry (ADHERE). Am Heart J 2005; 149:209-16.

2) Cleland JG, Swedberg K, Cohen-Solal A, et al. The Euro Heart Failure Survey of the EUROHEART survey programme: a survey on the quality of care among patients with heart failure in Europe: the Study Group on Diagnosis of the Working Group on Heart Failure of the European Society of Cardiology: the Medicines Evaluation Group Centre for Health Economics University of York. Eur J Heart Fail 2000;2: 
123-32.

3) Zannad F, Mebazaa A, Juillière Y, et al. Clinical profile, contemporary management and one-year mortality in patients with severe acute heart failure syndromes: the EFICA Study. Eur J Heart Fail 2006; 8:697-705.

4) Fonarow GC, Abraham WT, Albert NM, et al. Influence of a performance-improvement initiative on quality of care for patients hospitalized with heart failure: results of the organized program to initiate lifesaving treatment in hospitalized patients with heart failure (OPTIMIZE-HF). Arch Intern Med 2007; 167:1493-502.

5) Ronco C, Haapio M, House AA, Anavekar N, Bellomo R. Cardiorenal syndrome. J Am Coll Cardiol 2008;52:1527-39.

6) Gottlieb SS, Abraham W, Butler J, et al. The prognostic importance of different definitions of worsening renal function in congestive heart failure. J Card Fail 2002;8:136-41.

7) Schrier RW. Role of diminished renal function in cardiovascular mortality: marker or pathogenetic factor? J Am Coll Cardiol 2006;47: $1-8$

8) Klein L, Massie BM, Leimberger JD, et al. Admission or changes in renal function during hospitalization for worsening heart failure predict postdischarge survival: results from the Outcomes of a Prospective Trial of Intravenous Milrinone for exacerbations of Chronic Heart Failure (OPTIME-CHF). Circ Heart Fail 2008; 1:25-33.

9) Hunt SA, Abraham WT, Chin MH, et al. 2009 focused update incorporated into the ACC/AHA 2005 guidelines for the diagnosis and management of heart failure in adults: a report of the American College of Cardiology Foundation/American Heart Association Task Force on Practice Guidelines developed in collaboration with the Internaitional Society for Heart and Lung Transplantation. J Am Coll Cardiol 2009;53:e1-90.

10) Dickstein K, Cohen-Solal A, Filippatos G, et al. ESC guidelines for the diagnosis and treatment of acute and chronic heart failure 2008: the Task Force for the Diagnosis and Treatment of Acute and Chronic Heart Failure 2008 of the European Society of Cardiology: developed in collaboration with the Heart Failure Association of the ESC (HFA) and endorsed by the European Society of Intensive Care Medicine (ESICM). Eur Heart J 2008;29:2388-442.

11) Lindenfeld J, Albert NM, Boehmer JP, et al. HFSA 2010 comprehensive heart failure practice guideline. J Card Fail 2010;16:e1-194.

12) O'Meara E, Chong KS, Gardner RS, Jardine AG, Neilly JB, McDonagh TA. The modification of diet in renal disease (MDRD) equations provide valid estimations of glomerular filtration rates in patients with advanced heart failure. Eur J Heart Fail 2006;8:63-7.

13) Choi DJ, Han S, Jeon ES, et al. Characteristics, Outcomes and Predictors of Long-Term Mortality for Patients Hospitalized for Acute Heart Failure: A Report From the Korean Heart Failure Registry. Korean Circ J 2011;41:363-71.

14) Nohria A, Hasselblad V, Stebbins A, et al. Cardiorenal interactions: insights from the ESCAPE trial. J Am Coll Cardiol 2008;51:1268-74.

15) Smith GL, Lichtman JH, Bracken MB, et al. Renal impairment and outcomes in heart failure: systematic review and meta-analysis. $J$ Am Coll Cardiol 2006;47:1987-96.

16) Forman DE, Butler J, Wang Y, et al. Incidence, predictors at admission, and impact of worsening renal function among patients hospitalized with heart failure. J Am Coll Cardiol 2004;43:61-7.

17) Damman K, Navis G, Voors AA, et al. Worsening renal function and prognosis in heart failure: systematic review and meta-analysis. $J$ Card Fail 2007; 13:599-608.

18) Cowie MR, Komajda M, Murray-Thomas T, Underwood J, Ticho B; POSH Investigators. Prevalence and impact of worsening renal function in patients hospitalized with decompensated heart failure: results of the prospective outcomes study in heart failure (POSH). Eur Heart J 2006;27:1216-22.

19) Metra M, Nodari S, Parrinello G, et al. Worsening renal function in patients hospitalised for acute heart failure: clinical implications and prognostic significance. Eur J Heart Fail 2008; 10:188-95.

20) Damman K, Navis G, Smilde TD, et al. Decreased cardiac output, venous congestion and the association with renal impairment in patients with cardiac dysfunction. Eur J Heart Fail 2007;9:872-78.

21) McCullough PA, Ahmad A. Cardiorenal syndromes. World J Cardiol 2011;3:1-9

22) McAlister FA, Ezekowitz J, Tonelli M, Armstrong PW. Renal insufficiency and heart failure: prognostic and therapeutic implications from a prospective cohort study. Circulation 2004;109:1004-9.

23) Heywood JT, Fonarow GC, Costanzo MR, Mathur VS, Wigneswaran JR, Wynne J; ADHERE Scientific Advisory Committee and Investigators. High prevalence of renal dysfunction and its impact on outcome in 118,465 patients hospitalized with acute decompensated heart failure: a report from the ADHERE database. J Card Fail 2007;13: 422-30.

24) Mullens W, Abrahams Z, Francis GS, et al. Importance of venous congestion for worsening of renal function in advanced decompensated heart failure. J Am Coll Cardiol 2009;53:589-96.

25) Damman K, van Deursen VM, Navis G, Voors AA, van Veldhuisen DJ, Hillege HL. Increased central venous pressure is associated with impaired renal function and mortality in a broad spectrum of patients with cardiovascular disease. J Am Coll Cardiol 2009;53:582-8.

26) Drazner MH, Rame JE, Stevenson LW, Dries DL. Prognostic importance of elevated jugular venous pressure and a third heart sound in patients with heart failure. N Engl J Med 2001;345:574-81.

27) Damman K, Voors AA, Hillege HL, et al. Congestion in chronic systolic heart failure is related to renal dysfunction and increased mortality. Eur J Heart Fail 2010;12:974-82.

28) Uthoff $\mathrm{H}$, Breidthardt $\mathrm{T}$, Klima $\mathrm{T}$, et al. Central venous pressure and impaired renal function in patients with acute heart failure. Eur $J$ Heart Fail 2011;13:432-9.

29) Funaya H, Kitakaze M, Node K, Minamino T, Komamura K, Hori M. Plasma adenosine levels increase in patients with chronic heart failure. Circulation 1997;95:1363-5.

30) Metra M, O'Connor CM, Davison BA, et al. Early dyspnoea relief in acute heart failure: prevalence, association with mortality, and effect of rolofylline in the PROTECT Study. Eur Heart J 2011;32:1519-34.

31) Blankstein R, Bakris GL. Renal hemodynamic changes in heart failure. Heart Fail Clin 2008;4:411-23.

32) Francis GS, Benedict C, Johnstone DE, et al. Comparison of neuroendocrine activation in patients with left ventricular dysfunction with and without congestive heart failure: a substudy of the Studies of Left Ventricular Dysfunction (SOLVD). Circulation 1990;82:1724-9.

33) Chen HH, Schrier RW. Pathophysiology of volume overload in acute heart failure syndromes. Am J Med 2006;119:12(Supple 1):S11-6.

34) Masuo K, Lambert GW, Esler MD, Rakugi H, Ogihara T, Schlaich MP. The role of sympathetic nervous activity in renal injury and endstage renal disease. Hypertens Res 2010;33:521-8.

35) Schrier RW, Berl T, Anderson RJ. Osmotic and nonosmotic control of vasopressin release. Am J Physiol 1979;236:F321-32.

36) Schrier RW, Berl T. Nonosmolar factors affecting renal water excretion (first of two parts). N Engl J Med 1975;292:81-8.

37) Schrier RW, Berl T. Nonosmolar factors affecting renal water excretion (second of two parts). N Engl J Med 1975;292:141-5.

38) Haase-Fielitz A, Bellomo R, Devarajan P, et al. Novel and conventional serum biomarkers predicting acute kidney injury in adult cardiac surgery: a prospective cohort study. Crit Care Med 2009;37: 553-60.

39) Bonventre JV, Vaidya VS, Schmouder R, Feig P, Dieterle F. Next-generation biomarkers for detecting kidney toxicity. Nat Biotechnol 2010; 28:436-40.

40) Stevens LA, Coresh J, Greene T, Levey AS. Assessing kidney function: measured and estimated glomerular filtration rate. N Engl J Med 2006;354:2473-83.

41) Waikar SS, Bonventre JV. Creatinine kinetics and the definition of acute kidney injury. J Am Soc Nephrol 2009;20:672-9.

42) Filippatos G, Rossi J, Lloyd-Jones DM, et al. Prognostic value of blood urea nitrogen in patients hospitalized with worsening heart failure: insights from the Acute and Chronic Therapeutic Impact of a Va- 
sopressin Antagonist in Chronic Heart Failure (ACTIV in CHF) study. J Card Fail 2007; 13:360-4.

43) Cauthen CA, Lipinski MJ, Abbate A, et al. Relation of blood urea nitrogen to long-term mortality in patients with heart failure. Am J Cardiol 2008;101:1643-7.

44) Aronson D, Mittleman MA, Burger AJ. Elevated blood urea nitrogen level as a predictor of mortality in patients admitted for decompensated heart failure. Am J Med 2004;116:466-73.

45) Lindenfeld J, Schirier RW. Blood urea nitrogen: A marker for adverse effects of loop diuretics? J Am Coll Cardiol 2011;58:383-5.

46) Testani JM, Cappola TP, Brensinger CM, Shannon RP, Kimmel SE. Interaction between loop diuretic-associated mortality and blood urea nitrogen concentration in chronic heart failure. J Am Coll Cardiol 2011;58:375-82.

47) Schrier RW. Blood urea nitrogen and serum creatinine: not married in heart failure. Circ Heart Fail 2008; 1:2-5.

48) Mishra J, Ma Q, Prada A, et al. Identification of neutrophil gelatinaseassociated lipocalin as a novel early urinary biomarker for ischemic renal injury. J Am Soc Nephrol 2003;14:2534-43.

49) Zappitelli M, Washburn KK, Arikan AA, et al. Urine neutrophil gelatinase-associated lipocalin is an early marker of acute kidney injury in critically ill children: a prospective cohort study. Crit Care 2007;11: R84.

50) Aghel A, Shrestha K, Mullens W, Borowski A, Tang WH. Serum neutrophil gelatinase-associated lipocalin (NGAL) in predicting worsening renal function in acute decompensated heart failure. J Card Fail 2010;16:49-54.

51) Grubb A. Diagnostic value of analysis of cystatin $C$ and protein $H C$ in biological fluids. Clin Nephrol 1992;38(Suppl 1):S20-7.

52) Herget-Rosenthal S, Trabold S, Pietruck F, Holtmann M, Philipp T, Kribben A. Cystatin C: efficacy as screening test for reduced glomerular filtration rate. Am J Nephrol 2000;20:97-102.

53) Lassus JP, Nieminen MS, Peuhkurinen K, et al. Markers of renal function and acute kidney injury in acute heart failure: definitions and impact on outcomes of the cardiorenal syndrome. Eur Heart J 2010; 31:2791-8.

54) Ichimura $\mathrm{T}$, Bonventre JV, Bailly $\mathrm{V}$, et al. Kidney injury molecule-1 (KIM-1), a putative epithelial cell adhesion molecule containing a novel immunoglobulin domain, is up-regulated in renal cells after injury. J Biol Chem 1998;273:4135-42.

55) Damman K, van Veldhuisen DJ, Navis G, et al. Tubular damage in chronic systolic heart failure is associated with reduced survival independent of glomerular filtration rate. Heart 2010;96:1297-302.

56) Felker GM, Lee KL, Bull DA, et al. Diuretic strategies in patients with acute decompensated heart failure. N Engl J Med 2011;364:797-805.

57) Sarraf M, Masoumi A, Schrier RW. Cardiorenal syndrome in acute decompensated heart failure. Clin J Am Soc Nephrol 2009;4:2013-26.

58) Francis GS, Siegel RM, Goldsmith SR, Olivari MT, Levine TB, Cohn JN. Acute vasoconstrictor response to intravenous furosemide in patients with chronic congestive heart failure: activation of the neu- rohumoral axis. Ann Intern Med 1985;103:1-6.

59) Konstam MA, Gheorghiade M, Burnett JC Jr, et al. Effects of oral tolvaptan in patients hospitalized for worsening heart failure: the EVEREST Outcome Trial. JAMA 2007;297:1319-31.

60) Costello-Boerrigter LC, Smith WB, Boerrigter G, et al. Vasopressin-2receptor antagonism augments water excretion without changes in renal hemodynamics or sodium and potassium excretion in human heart failure. Am J Physiol Renal Physiol 2006;290:F273-8.

61) Maskin CS, Ocken S, Chadwick B, LeJemtel TH. Comparative systemic and renal effects of dopamine and angiotensin-converting enzyme inhibition with enalaprilat in patients with heart failure. Circulation 1985;72:846-52.

62) Friedrich JO, Adhikari N, Herridge MS, Beyene J. Meta-analysis: low-dose dopamine increases urine output but does not prevent renal dysfunction or death. Ann Intern Med 2005;142:510-24.

63) Giamouzis G, Butler J, Starling RC, et al. Impact of dopamine infusion on renal function in hospitalized heart failure patients: results of the Dopamine in Acute Decompensated Heart Failure (DAD-HF) Trial. J Card Fail 2010;16:922-30.

64) Leier CV, Heban PT, Huss P, Bush CA, Lewis RP. Comparative systemic and regional hemodynamic effects of dopamine and dobutamine in patients with cardiomyopathic heart failure. Circulation 1978;58(3 Pt 1):466-75.

65) Yilmaz MB, Yalta K, Yontar C, et al. Levosimendan improves renal function in patients with acute decompensated heart failure: comparison with dobutamine. Cardiovasc Drugs Ther 2007;21:431-5.

66) Mebazaa A, Nieminen MS, Packer M, et al. Levosimendan vs dobutamine for patients with acute decompensated heart failure: the SURVIVE Randomized Trial. JAMA 2007;297:1883-91.

67) Den Uil CA, Lagrand WK, Spronk PE, et al. Low-dose nitroglycerin improves microcirculation in hospitalized patients with acute heart failure. Eur J Heart Fail 2009;11:386-90.

68) Mullens W, Abrahams Z, Francis GS, et al. Sodium nitroprusside for advanced low-output heart failure. J Am Coll Cardiol 2008;52:200-7.

69) Teichman SL, Unemori E, Dschietzig T, et al. Relaxin, a pleiotropic vasodilator for the treatment of heart failure. Heart Fail Rev 2009;14: 321-9.

70) O'Connor CM, Starling RC, Hernandez AF, et al. Effect of nesiritide in patients with acute decompensated heart failure. $N$ Engl $J$ Med 2011;365:32-43.

71) Ljungman S, Kjekshus J, Swedberg K. Renal function in severe congestive heart failure during treatment with enalapril (the Cooperative North Scandinavian Enalapril Survival Study [CONSENSUS] Trial). Am J Cardiol 1992; 70:479-87.

72) Bourge RC, Tallaj JA. Ultrafiltration: a new approach toward mechanical diuresis in heart failure. J Am Coll Cardiol 2005;46:2052-3.

73) Costanzo MR, Guglin ME, Saltzberg MT, et al. Ultrafiltration versus intravenous diuretics for patients hospitalized for acute decompensated heart failure. J Am Coll Cardiol 2007;49:675-83. 